\title{
HUBUNGAN KINERJA OTAK DENGAN SPIRITUALITAS DIUKUR DENGAN MENGGUNAKAN INDONESIA SPIRITUAL HEALTH ASSESSMENT PADA TOKOH-TOKOH AGAMA KRISTEN GMIST (PENDETA) DI RESORT TAHUNA
}

\author{
${ }^{1}$ Mirachel. D. Samel \\ ${ }^{2}$ Taufiq Pasiak \\ ${ }^{2}$ Shane. H. R. Ticoalu \\ ${ }^{1}$ Kandidat Skripsi Fakultas kedokteran Universitas sam ratulangi Manado \\ ${ }^{2}$ Bagian Anatomi - Histologi Fakultas Kedokteran Universitas Sam Ratulangi Manado \\ Email : mirachel_samel@yahoo.co.id
}

\begin{abstract}
Neuroscience is a science about the nervous system. The development of neuroscience has touched the spiritual dimension. There are four things if combined will result spirituality, they are meaning of life, positive emotions, spiritual experience and rituals. Daniel Amen divides brain into five major systems namely prefrontal cortex, limbic system, basal ganglia, gyrus cingulatus, and temporal lobes. Indonesia Spiritual Health Assessment (ISHA) is a tools that can measure and describe the correlation of spirituality with brain. This study aimed to determine the correlation between the brain performance with the spirituality in christian religious leaders GMIST (pastor) at resort Tahuna. This was a descriptive studywith analytical survey method. Sample of this research was GMIST pastors amount of 33 people. The Spearman correlation test showed a $P$ value 0.017 between the basal ganglia and spiritual experience which indicated that the correlation was significant. Conclusion: There was significant correlation between the brain performance with the human spirituality measured by using ISHA in Christian religion leaders GMIST (pastors) at Tahuna resort.
\end{abstract}

Keywords: brain, ISHA, Christian religious leaders, spirituality

\begin{abstract}
Abstrak: Neurosains adalah ilmu yang mempelajari mengenai sistem saraf. Perkembangan neurosains telah menyentuh dimensi spiritual. Terdapat empat hal bila digabungkan menghasilkan spiritual yaitu makna hidup, emosi positif, pengalaman spiritual dan ritual. Daniel Amen membagi otak dalam lima sistem utama yaitu korteks prefrontalis, sistem limbik, ganglia basalis, girus singulatus, dan lobus temporalis. Indonesia Spiritual Health Assessment (ISHA) adalah alat yang digunakan untuk mengukur hubungan spiritualitas dengan otak. Tujuan penelitian ini adalah untuk mengetahui hubungan kinerja otak dengan spiritualitas pada pendeta GMIST di Resort Tahuna. Jenis penelitian yang digunakan ialah deskriptif dengan metode survei analitik. Sampel penelitian adalah pendeta-pendeta GMIST di Resort Tahuna sebanyak 33 orang. Data penelitian dianalisis dengan uji korelasi spearman. Hasil uji korelasi spearman antara ganglia basalis dan pengalaman spiritual menunjukan nilai $P=0,017$ ini berarti kedua variabel memiliki hubungan yang bermakna. Simpulan: Terdapat hubungan bermakna antara kinerja otak dan spiritualitas manusia diukur dengan menggunakan ISHA pada tokoh-tokoh agama kristen GMIST (pendeta) di Resort Tahuna.
\end{abstract}

Kata kunci: otak, ISHA, tokoh agama Kristen, spiritualitas 
Neurosains adalah ilmu yang mempelajari tentang seluruh hal, embriologi, anatomi, fisiologi, biokimia, farmakologi atau aspek lain yang berkaitan dengan sistem saraf termasuk otak. ${ }^{1,2}$

Otak memiliki peranan yang sangat penting bagi manusia dimana otak sendiri berfungsi sebagai pusat pengelola informasi, mengatur setiap keseimbangan gerakan, serta berfungsi dalam mengatur cara berpikir dan berperilaku pada manusia itu sendiri., ${ }^{2,3}$ Otak memiliki beberapa komponen yang mencirikhasinya yaitu korteks serebri, korteks prefrontal, area broca dan wernicke, dan homunculus. ${ }^{4}$

Daniel Amen membagi otak ke dalam 5 bagian yaitu terdiri atas : korteks prefrontalis, sistem limbik, ganglia basalis, girus singulatus, serta lobus temporalis. ${ }^{4}$

Spiritualitas adalah merupakan suatu pengalaman empirik manusia yang mempunyai kaitan dengan tujuan dan makna hidup dalam kaitan dengan hubungan interpersonal antar manusia (sosial-interpersonal) dan kehidupan secara keseluruhan sebagai manifestasi hubungannya dengan Tuhan. ${ }^{4-6}$

Spiritualitas memiliki fungsi yang sangat penting dalam pencarian akan makna hidup, karena makna hidup sendiri merupakan komponen dasar dari spiritualitas. $^{4} \quad$ Spiritualitas itu sendiri mempunyai 4 dimensi yang ikut terlibat di dalamnya yaitu meliputi makna hidup, emosi positif, pengalaman akan spiritual, dan ritual. ${ }^{4}$

Indonesia Spiritual Health Assessment (ISHA) adalah alat ukur yang digunakan untuk pemeriksaan tingkat spiritualitas yang bisa dilakukan pada setiap orang, ISHA sendiri terdiri dari beberapa komponen yang terdapat di dalamnya yaitu spiritual brain item, brain system assessment, dan neurobiofeedback. ${ }^{4}$

Tujuan penelitian yang dilakukan adalah untuk mengetahui hubungan kinerja otak dan spiritualitas manusia pada tokohtokoh agama kristen GMIST (pendeta) di Resort Tahuna.

\section{METODE PENELITIAN}

Jenis penelitian yang dilakukan adalah penelitian deskriptif dengan menggunakan metode survei analitik. Penelitian ini dilakukan di kota Tahuna, kabupaten Sangihe, provinsi Sulawesi Utara, tepatnya di Resort GMIST Tahuna pada November 2013. Populasi dan sampel penelitian ini adalah para pendeta-pendeta di Resort GMIST Tahuna yang masih aktif melayani yang berjumlah 33 orang terdiri dari 12 laki-laki dan 21 perempuan diambil secara random sampling dengan kriteria inklusi : laki-laki atau perempuan, pendeta yang aktif melayani, pendidikan minimal strata satu, dan bersedia untuk diwawancarai.

Cara pengambilan data dengan membagikan kuesioner berupa Indonesia Spiritual Health Assessment (ISHA) kepada setiap responden.

\section{Pengolahan dan Analisis Data}

Pengolahan dan Analisis data dilakukan setelah data penelitian telah lengkap yakni ketika kuesioner yang dibagikan telah diisi responden tanpa melewatkan pertanyaanpertanyaan yang sudah tertera di dalam kuesioner. Data dalam penelitian ini dianalisis dengan menggunakan uji korelasi spearman yang ada pada aplikasi SPSS versi 20. Makna hubungan di antara dua variabel dilihat pada signifikan (p) dengan nilai ketentuan significan $<\alpha$ dimana nilai $\alpha$ yang diambil adalah 0,05 . Nilai koefisian korelasi (r) ada di antara -1 dan +1 , jika r mendekati -1 , berarti kedua variabel memiliki hubungan negatif, sedangkan jika $r$ mendekati +1 , berarti kedua variabel memiliki hubungan positif.

\section{Hasil Interpretasi ISHA}

Hasil interpretasi dari ISHA terbagi atas dua yaitu spiritualitas dan dominasi otak yang keduanya dikategorikan dalam tiga bentuk yakni excellent yang berarti sangat baik, moderate berarti baik, dan improved yang berarti cukup baik. Tabel hasil interpretasi ISHA sebagai berikut : 
Tabel 1. Hasil ISHA Spiritualitas

\begin{tabular}{cccccc}
\hline \multirow{2}{*}{ jenis Kelamin } & Interpretasi & $\begin{array}{c}\text { Pengalaman } \\
\text { Spiritual }\end{array}$ & $\begin{array}{c}\text { Emosi } \\
\text { Positif }\end{array}$ & $\begin{array}{c}\text { Makna } \\
\text { Hidup }\end{array}$ & Ritual \\
\hline Laki-laki & Excellent & 0 & 8 & 11 & 8 \\
& Moderate & 9 & 4 & 1 & 4 \\
& Improved & 3 & 0 & 0 & 0 \\
\hline \multirow{2}{*}{ Perempuan } & Excellent & 3 & 20 & 21 & 20 \\
& Moderate & 17 & 1 & 0 & 1 \\
& Improved & 1 & 0 & 0 & 0 \\
\hline
\end{tabular}

Tabel 2. Hasil ISHA Dominasi Otak

\begin{tabular}{ccccccc}
\hline $\begin{array}{c}\text { Jenis } \\
\text { Kelamin }\end{array}$ & Interpretasi & $\begin{array}{c}\text { Korteks } \\
\text { Prefrontalis }\end{array}$ & $\begin{array}{c}\text { Sistem } \\
\text { Limbik }\end{array}$ & $\begin{array}{c}\text { Ganglia } \\
\text { Basalis }\end{array}$ & $\begin{array}{c}\text { Gyrus } \\
\text { Cingulatus }\end{array}$ & $\begin{array}{c}\text { Lobus } \\
\text { Temporalis }\end{array}$ \\
\hline Laki-laki & Excellent & 10 & 5 & 6 & 5 & 8 \\
& Moderate & 2 & 7 & 6 & 7 & 4 \\
& Improved & 0 & 0 & 0 & 0 & 0 \\
\hline \multirow{2}{*}{ Perempuan } & Excellent & 15 & 7 & 14 & 11 & 7 \\
& Moderate & 6 & 14 & 7 & 10 & 13 \\
& Improved & 0 & 0 & 0 & 0 & 1 \\
\hline
\end{tabular}

\section{Hasil Analisis Data}

Hasil analisis yang akan dilakukan pada data yang telah didapatkan, selanjutnya dilakukan uji korelasi antara otak dan spiritualitas yang keduanya diwakili oleh komponennya masing-masing. Komponenkomponen tersebut adalah antara pengalaman spiritual dengan ganglia basalis, korteks prefrontalis dan makna hidup, emosi positif dan sistem limbik, serta sistem limbik dan ritual. Uji korelasi yang digunakan adalah spearman, ini dikarenakan kedua variabel kategorik (kualitatif) yang merupakan skala ordinal. Korelasi spearman yang digunakan adalah dengan SPSS versi 20. Hubungan yang bermakna di antara kedua variabel tersebut bisa dilihat pada nilai signifikan (p) dengan dasar bahwa nilai signifikan $<\alpha$, dimana nilai $\alpha$ tersebut adalah 0,05. Nilai koefisien korelasi (r) berada antara -1 dan +1 . Jika nilai $r$ mendekati dengan -1 maka kedua variabel tersebut memiliki hubungan yang negatif, begitu pula sebaliknya, jika $\mathrm{r}$ mendekati +1 maka kedua variabel memiliki hubungan positif. Hasil korelasi dapat dilihat pada tabel. 
Tabel 3. Korelasi Pengalaman Spiritual dan Ganglia Basalis

\begin{tabular}{|c|c|c|c|c|}
\hline & & & $\begin{array}{c}\text { Pengalaman } \\
\text { Spiritual }\end{array}$ & $\begin{array}{l}\text { Ganglia } \\
\text { Basalis }\end{array}$ \\
\hline & $\begin{array}{c}\text { Pengalaman } \\
\text { Spiritual }\end{array}$ & $\begin{array}{l}\text { Correlation } \\
\text { Coefficient }\end{array}$ & 1,000 &,- 414 \\
\hline \multirow[t]{3}{*}{ Spearman's rho } & & $\begin{array}{c}\text { Sig. (2-tailed) } \\
\mathrm{N}\end{array}$ & $\begin{array}{c}- \\
33\end{array}$ & $\begin{array}{c}, 017 \\
33\end{array}$ \\
\hline & $\begin{array}{l}\text { Ganglia } \\
\text { Basalis }\end{array}$ & $\begin{array}{l}\text { Correlation } \\
\text { Coefficient }\end{array}$ &,- 414 & 1,000 \\
\hline & & $\begin{array}{c}\text { Sig. (2-tailed) } \\
\text { N }\end{array}$ & $\begin{array}{c}, 017 \\
33\end{array}$ & $\begin{array}{c}- \\
33\end{array}$ \\
\hline
\end{tabular}

Tabel 4. Korelasi Korteks Prefrontalis dan Makna Hidup

\begin{tabular}{|c|c|c|c|c|}
\hline & & & $\begin{array}{c}\text { Korteks } \\
\text { Prefrontalis }\end{array}$ & $\begin{array}{l}\text { Makna } \\
\text { Hidup }\end{array}$ \\
\hline & $\begin{array}{c}\text { Korteks } \\
\text { Prefrontalis }\end{array}$ & $\begin{array}{l}\text { Correlation } \\
\text { Coefficient }\end{array}$ & 1,000 & ,172 \\
\hline \multirow[t]{3}{*}{ Spearman's rho } & & $\begin{array}{c}\text { Sig. (2-tailed) } \\
\mathrm{N}\end{array}$ & $\begin{array}{l}- \\
33\end{array}$ & $\begin{array}{c}, 338 \\
33\end{array}$ \\
\hline & $\begin{array}{l}\text { Makna } \\
\text { Hidup }\end{array}$ & $\begin{array}{l}\text { Correlation } \\
\text { Coefficient }\end{array}$ & 172 & 1,000 \\
\hline & & $\begin{array}{c}\text { Sig. (2-tailed) } \\
\mathrm{N}\end{array}$ & $\begin{array}{c}\text {,338 } \\
33\end{array}$ & $\begin{array}{c}- \\
33\end{array}$ \\
\hline
\end{tabular}


Tabel 5. Korelasi Emosi Positif dan Sistem Limbik

\begin{tabular}{|c|c|c|c|c|}
\hline & & & $\begin{array}{l}\text { Emosi } \\
\text { Positif }\end{array}$ & $\begin{array}{l}\text { Sistem } \\
\text { Limbik }\end{array}$ \\
\hline & $\begin{array}{l}\text { Emosi } \\
\text { Positif }\end{array}$ & $\begin{array}{l}\text { Correlation } \\
\text { Coefficient }\end{array}$ & 1,000 &,- 301 \\
\hline \multirow[t]{3}{*}{ Spearman's rho } & & $\begin{array}{c}\text { Sig. (2-tailed) } \\
\mathrm{N}\end{array}$ & $\begin{array}{c}- \\
33\end{array}$ & $\begin{array}{c}, 089 \\
33\end{array}$ \\
\hline & $\begin{array}{l}\text { Sistem } \\
\text { Limbik }\end{array}$ & $\begin{array}{l}\text { Correlation } \\
\text { Coefficient }\end{array}$ &,- 301 & 1,000 \\
\hline & & $\begin{array}{c}\text { Sig. (2-tailed) } \\
\text { N }\end{array}$ & $\begin{array}{c}, 089 \\
33\end{array}$ & $\begin{array}{c}- \\
33\end{array}$ \\
\hline
\end{tabular}

Tabel 6. Korelasi Sistem Limbik dan Ritual

\begin{tabular}{|c|c|c|c|c|}
\hline & & & $\begin{array}{l}\text { Sistem } \\
\text { Limbik }\end{array}$ & Ritual \\
\hline & $\begin{array}{l}\text { Sistem } \\
\text { Limbik }\end{array}$ & $\begin{array}{l}\text { Correlation } \\
\text { Coefficient }\end{array}$ & 1,000 &,- 033 \\
\hline \multirow[t]{3}{*}{ Spearman's rho } & & $\begin{array}{c}\text { Sig. (2-tailed) } \\
\mathrm{N}\end{array}$ & $\begin{array}{c}- \\
33\end{array}$ & $\begin{array}{c}, 857 \\
33\end{array}$ \\
\hline & Ritual & $\begin{array}{l}\text { Correlation } \\
\text { Coefficient }\end{array}$ &,- 033 & 1,000 \\
\hline & & $\begin{array}{c}\text { Sig. (2-tailed) } \\
\mathrm{N}\end{array}$ & $\begin{array}{c}, 857 \\
33\end{array}$ & $\begin{array}{c}- \\
33\end{array}$ \\
\hline
\end{tabular}

\section{BAHASAN}

Sampel yang diambil dalam penelitian ini adalah para tokoh-tokoh agama kristen GMIST (pendeta) yang berada di resort Tahuna yang terdiri dari 12 laki-laki dan 21 perempuan.

Pada tabel 1 Hasil ISHA spiritualitas didapatkan pengalaman spiritual laki-laki yang excellent tidak ada, moderate 9 orang, improved 3 orang. Pengalaman spiritual perempuan yang excellent 3 orang, moderate 17 orang, improved 1 orang. Emosi positif laki-laki yang excellent 8 orang, moderate 4 orang, improved tidak ada. Emosi positif perempuan yang excellent 20 orang, moderate 1 orang dan improved tidak ada. Makna hidup, laki-laki yang excellent 11 orang, moderate 1 orang, improved tidak ada. Makna hidup, perempuan yang excellent 21 orang, moderate, dan improved tidak ada. Ritual laki-laki yang excellent 8 orang, moderate 4 orang, improved tidak ada. Ritual pada perempuan yang excellent 20 orang, moderate 1 orang, improved tidak ada. 
Pada tabel 2 Hasil ISHA dominasi otak didapatkan korteks prefrontalis laki-laki yang excellent 10 orang, moderate 2 orang, improved tidak ada, sedangkan pada perempuan excellent 15 orang, moderate 6 orang, improved tidak ada. Sistem limbik pada laki-laki yang excellent 5 orang, moderate 7 orang, improved tidak ada, pada perempuan yang excellent 7 orang, moderate 14 orang, improved tidak ada. Ganglia basalis pada laki-laki yang excellent 6 orang, moderate 6 orang, improved tidak ada, pada perempuan yang excellent 14 orang, moderate 7 orang, improved tidak ada. Girus singulatus pada laki-laki yang excellent 5 orang, moderate 7 orang, improved tidak ada, pada perempuan yang excellent 11 orang, moderate 10 orang, improved tidak ada. Lobus temporalis pada laki-laki yang excellent 8 orang, moderate 4 orang, improved tidak ada, pada perempuan yang excellent 7 orang, moderate 13 orang, improved 1 orang.

Pada tabel 3 adalah hasil korelasi antara otak dan spiritualitas yakni antara pengalaman spiritual dan ganglia basalis, didapatkan nilai $\mathrm{p}=0,017$ yang berarti bahwa keduanya mempunyai hubungan yang bermakna. Untuk nilai koefisien korelasi didapatkan -0,414 yang berarti kedua variabel memiliki hubungan cukup dengan pola negatif.

Pada tabel 4 adalah hasil korelasi antara korteks prefrontalis dan makna hidup didapatkan nilai $\mathrm{p}=0,338$ dan koefisien korelasi 0,172 berdasarkan nilai korelasi tersebut menunjukan tidak ada hubungan antara kedua variabel tersebut.

Pada Tabel 5 adalah hasil korelasi antara emosi positif dan sistem limbik didapatkan nilai dari $\mathrm{p}=0,089$ dan nilai koefisien korelasi -0,301 ini menunjukan bahwa kedua variabel tidak memiliki hubungan

Pada Tabel 6 adalah hasil korelasi antara sistem limbik dan ritual didapatkan nilai $\mathrm{p}=0,857$ dan koefisien korelasi 0,033 ini berarti kedua variabel tidak ada hubungan.
Dari hasil korelasi yang telah dibuat antara otak dan spiritualitas didapatkan ada 2 variabel yang positif memiliki hubungan yang saling terikat/mempengaruhi yaitu antara pengalaman spiritual dan ganglia basalis.

\section{SIMPULAN}

Dari penelitian yang sudah dilakukan disimpulkan bahwa terdapat hubungan yang bermakna antara kinerja otak dan spiritualitas dalam hal ini terdapat pada pengalaman spiritual dan ganglia basalis yang diukur dengan menggunakan ISHA pada tokoh-tokoh agama kristen GMIST (pendeta) di Tahuna.

\section{SARAN}

Dalam penelitian yang lebih lanjut, sebaiknya digunakan jumlah sampel yang lebih besar untuk mendapatkan hasil yang lebih akurat.

\section{DAFTAR PUSTAKA}

1. Dorland WAN. Kamus Kedokteran Dorland edisi 31. Jakarta : EGC; 2010.

2. Hernata I. Ilmu kedokteran lengkap tentang neurosains. Jogjakarta: DMedika; 2013.

3. Guyton CA, Hall J. Buku Ajar Fisiologi Kedokteran edisi 11. Jakarta: EGC; 2008.

4. Pasiak T. Tuhan dalam Otak Manusia: Mewujudkan kesehatan spiritual berdasarkan neurosains. Bandung: Mizan; 2012.

5. Liwarti. Hubungan pengalaman spiritual dengan psychological well being pada penghuni lembaga pemasyarakatan. jurnal sains dan praktik psikologi.2013, 1(1) : 7788.

6. Rosito A.C. Spiritualitas dalam prespektif Psikologi Positif.2010, 18(1) :29-42 